\title{
Evaluasi Kesuksesan Web Desa Pada Kecamatan Maesan Menggunakan Information System Success Model (ISSM)
}

\author{
Oktalia Juwita $^{1}$, Vian Elfada ${ }^{2}$, Priza Pandunata ${ }^{3}$ \\ Fakultas Ilmu Komputer, Universitas Jember \\ oktalia@unej.ac.id, velfada@gmail.com,priza@unej.ac.id
}

\begin{abstract}
ABSTRAK
Web Desa adalah situs berbasis online yang di dalamnya terdapat informasi seputar desa yang dioperasikan oleh PPID (Petugas Pengelola Informasi Desa). Saat ini PPID di Kecamatan Maesan jarang melakukan update informasi setiap harinya. Hal itu disebabkan karena PPID kebanyakan belum bisa untuk melakukan posting dan kesulitan untuk membuat beritanya. Penelitian ini akan mengevaluasi Web Desa dengan menggunakan metode Information System Success Model (ISSM). Tujuan dari penelitian ini adalah untuk mengetahui faktor-faktor yang mendukung dan menghambat kesuksesan dari Web Desa. Data yang digunakan yaitu 61 responden yang terdiri dari PPID dari setiap desa. Penelitian ini menggunakan aplikasi GeSCA untuk uji hipotesisnya dan SPSS untuk uji validitas dan reliabelitasnya. Hasil dari penelitian ini menunjukkan jika variabel Use berpengaruh positif dan signifikan terhadap variabel Net Benefits dan Net Benefits berpengaruh positif dan signifikan terhadap Use.
\end{abstract}

Keyword: Web Desa, PPID, ISSM, GeSCA

\section{Pendahuluan}

Petugas Pengelola Informasi Desa (PPID) adalah pelaksana fungsi penyelengaraan pemerintah desa khususnya untuk untuk mengelola, memperbaharui, menyediakan dan pemberi layanan informasi serta layanan administrasi lain yang berbasis teknologi informasi baik online maupun offline melalui web desa[11]. PPID berkedudukan di desa yang dibentuk oleh peraturan Kepala Desa (Perkades). PPID memiliki 5 anggota yaitu Kepala Desa selaku Ketua PPID, Sekertaris Desa selaku Sekertaris PPID, Kepala Urusan Pemerintahan selaku Koordinator Pelaksana Teknis serta Operator yang ditunjuk langsung oleh Kepala Desa.

Website desa ini dikelola oleh aparat desa yang sudah dimandati SK oleh Kepala Desa atau pihak lain yang masih ada kaitannya dengan aparat desa secara sah dan legal [15]. Aparat desa yang dimandati oleh Kepala Desa akan memberikan informasi yang sesuai dengan fakta keadaan dari desa tersebut. Fakta tersebut bisa berupa kondisi lingkungan, kegiatan desa, rapat perangkat desa dan kegiatan lainnya. Aparat desa yang bertugas dalam memberikan informasi tersebut adalah Petugas Pengelola Informasi Desa (PPID). PPID diwajibkan untuk menerbitkan minimal satu berita setiap harinya agar informasi kegiatan menjadi terbuka untuk umum.

Saat ini PPID di Kecamatan Maesan jarang melakukan update informasi setiap harinya. Hal itu disebabkan karena PPID kebanyakan belum bisa untuk melakukan posting dan kesulitan untuk membuat beritanya. Tidak hanya itu, dalam pelaksanaanya terdapat beberapa masalah juga diantaranya adalah web desa sering terputus dari server, masih banyak terjadinya $b u g$, minat masyarakat untuk memanfaatkan web desa juga masih kurang, serta masih belum banyak masyarakat yang mengetahui tentang layanan web desa dan lain sebagainya.

Untuk mengetahui informasi yang diberikan oleh PPID telah akurat dan diperbarui setiap waktunya atau belum dan untuk mengurangi permasalahan-permasalahan yang ada maka harus dilakukan evaluasi pada web desa. Evaluasi dilakukan karena pada web desa update informasi jarang dilakukan serta adanya permasalahan saat PPID mengelola web desa. Namun di sisi yang lain pengukuran atau penilaian kesuksesan suatu sistem informasi yang efektif dalam pengelolaan web desa sulit dilakukan. Kesulitan penilaian kesuksesan dan keefektifan sebuah sistem informasi mendorong banyak peneliti mengembangkan model untuk menilai kesuksesan sebuah sistem informasi.

Berdasarkan uraian diatas, maka perlu dilakukan evaluasi terhadap web desa untuk mengetahui kesalahan dan permasalahan yang terdapat didalamnya dengan menerapkan faktor-faktor kesuksesan. Web Desa yang sukses adalah web desa yang dapat memberikan dampak positif terhadap suatu desa baik dari segi wisata, kebudayaan, dan bisnis. 
Untuk mengukur faktor-faktor kesuksesan yang mempengaruhi sistem digunakan model penelitian yaitu, Information System Success Model (ISSM). Proses dan pertimbangan sebab akibat dari model yang memiliki enam dimensi konstruksi dan saling terikat yaitu Information Quality, System Quality, Service Quality, Use, User Satisfaction untuk mengertahui kesuksesan ke dalam Net Benefit [3]. Keterkaitan antar dimensi memiliki tujuan yang penting untuk mengukur, menganalisis, serta melaporkan kesuksesan sistem informasi yang berkualitas. ISSM dipilih karena memiliki variabel dan indikator yang selaras dengan permasalahan yang dihadapi dan telah menyelesaikan masalah-masalah serupa pada penelitian-penelitian terdahulu.

\section{Metodologi Penelitian}

Metodologi penelitian merupakan penggambaran penelitian yang akan dilakukan untuk menjawab rumusan masalah sehingga dapat mewujudkan tujuan sebenarnya dari penelitian.

\subsection{Jenis Penellitian}

Jenis penelitian yang digunakan dalam penelitian ini adalah penelitian kuantitatif. Penelitian kuantitatif merupakan sebuah penelitian yang menggunakan data numerik pada proses penelitiannya dan hasilnya bersifat objektif menggunakan analisis statistik [1].

\subsection{Tahapan Penelitian}

Peneliti memiliki beberapa tahapan penelitian, berikut penjelasannya:

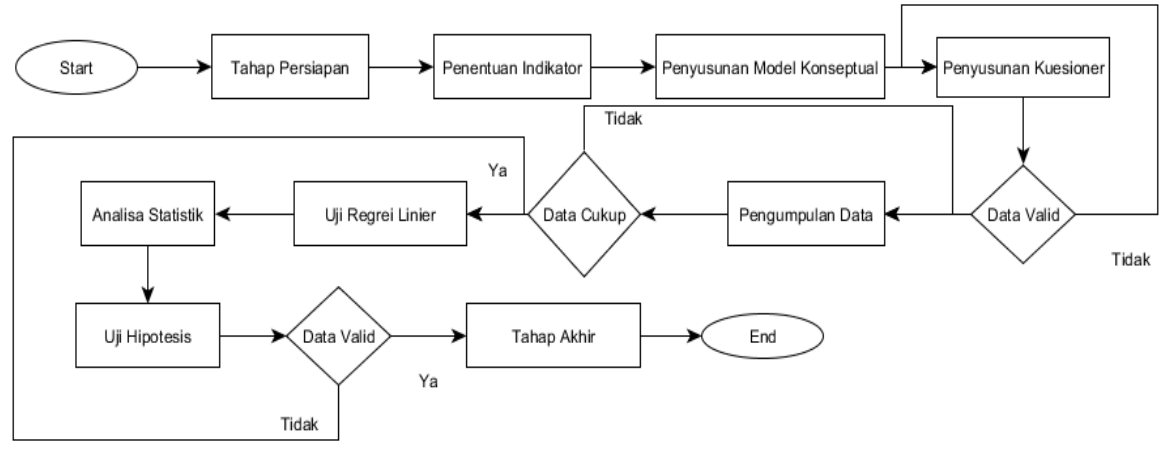

Gambar 1 Tahapan Penelitian

Gambar 1 menjelaskan tentang alur penelitian yang menerapkan metode Information System Success Model (ISSM) dalam proses evaluasi kesuksesan Web Desa.

\subsection{Data, Populasi dan Sampel}

Sumber data yang digunakan dalam penelitian berasal dari data primer dan data sekunder. Data primer adalah data yang diperoleh langsung dari responden melalui metode pengumpulan data berupa kuesioner. Pembagian kuesioner penelitian dilakukan secara online dengan perangkat google forms. Kuesioner dikirim secara online kepada seluruh PPID di Kecamatan Maesan melalui alamat email masing-masing satuan kerja. Proses pengumpulan data dilakukan selama kurang lebih 3 pekan, sejak tanggal 1 Februari s.d. 23 Februari 2019. Sedangkan data sekunder adalah data yang diperoleh dan disajikan oleh pihak-pihak lainnya seperti Kantor Kecamatan Maesan, Kantor kabupaten Bondowoso dan Dinas Kominfo Bondowoso. Populasi dalam penelitian ini adalah seluruh operator (user) atau petugas petugas pengelola informasi desa (PPID), yaitu berjumlah 61 orang. User atau pengguna sistem ini berasal dari kantor desa, Kecamatan Maesan.

\subsection{Variabel Penelitian}

Penelitian ini menggunakan 6 variabel dari model yang dikeluarkan oleh [3] yaitu terdiri dari variabel eksogen dan variabel endogen. Varibel eksogen adalah variabel independen (bebas) yang mempengaruhi variabel dependen (terikat) yang ditunjukkan dengan adanya anak panah yang berasal dari variabel tersebut menuju variabel endogen dalam model. Sedangkan variabel endogen adalah variabel dependen (terikat) yang dipengaruhi oleh variabel independen (bebas) yang ditunjukkan dengan adanya anak panah yang menuju variabel tersebut dalam model. Variabel eksogen penelitian ini terdiri atas kualitas sistem (system quality) dan kualitas Sedangkan variabel endogen penelitian ini terdiri atas:

Variabel yang digunakan dalam penelitian ini terdiri dari enam variabel yaitu:

1. Variabel Kualitas Sistem (System Quality)

Indikator yang digunakan yaitu:

a. Kenyamanan Akses

b. Keluwesan Sistem(Flexibility)

c. Realisasi dari ekspektasi-ekspektasi pemakai

d. Kegunaan dari fungsi-fungsi spesifik 
2. Variabel Kualitas Informasi (Information Quality)

Indikator yang digunakan yaitu:

a. Kelengkapan(Completeness)

b. Relevan (Relevance)

c. Akurat (Accurate)

d. ketepatan waktu (Timeliness)

e. Bentuk (Format)

3. Variabel Kualitas Layanan

Indikator yang digunakan yaitu :

a. Kecepatan respon

b. Kemampuan teknik

c. Pelayanan setelahnya

4. Variabel Penggunaan Sistem (Use)

Variabel ini diukur dengan indikator yang hanya terdiri dari satu item

yaitu frequency of use.

5. Variabel Kepuasan Pengguna (User Satisfaction)

Indikator yang digunakan yaitu :

a. Efesiensi (Efficiency)

b. Keefektivan (Effectiveness)

c. Kepuasan (Satisfaction)

6. Variabel manfaat-manfaat bersih (Net benefit)

Indikator yang digunakan yaitu :

a. Improve Knowledge

b. Reduce Information Search time

c. Productivity

\subsection{Uji Regeresi Linier Sederhana}

Dalam penelitian akan dilakukan uji regres linier sederhana yaitu uji validitas dan reliabilitas, di mana validitas merupakan ukuran tentang seberapa cermat suatu uji atau alat ukur dapat melakukan fungsi ukurnya, sedangkan reliabilitas menunjukkan sejauh mana pengukuran tersebut dapat memberikan hasil yang konsisten bila dilakukan pengukuran kembali terhadap subyek yang sama. case study ini menggunakan alat Uji Validitas dan Reliabilitas menggunakan Microsoft Stastical Package for Social Sciense (SPSS) versi 23.0. Pengujian validitas untuk setiap variabel pada pengukuran kesuksesan sitem teknologi informasi terhadap seluruh pertanyaan jika lebih besar dari $\mathrm{r}$ table untuk $\mathrm{N}=30$ pada tingkat signifikansi $5 \%$ yaitu sebesar 0,361 . Hal ini menunjukkan bahwa semua pertanyaan adalah signifikan dan dapat dinyatakan valid. Pengujian reliabilitas dilakukan dengan menggunakan koefisien reliabilitas Cronbach's alpha, terhadap item-item yang tersisa dalam setiap variabel setelah dilakukan analisis faktor. Secara umum, reliabilitas sekitar 0,7 dianggap dapat diterima (acceptable) dan di atas 0,8 dianggap bagus [8].

\subsection{Hipotesis}

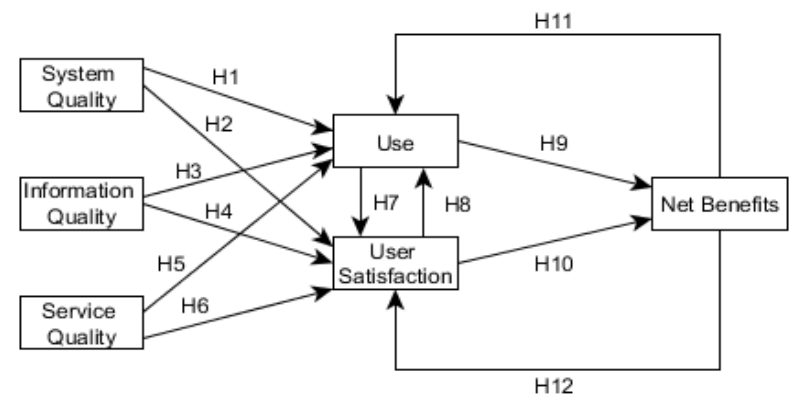

Gambar 2 Model Konseptual Penelitian

Berdasarkan Model DeLone and McLean pada Gambar 2 diperoleh sebuah usulan hipotesis awal yaitu sebagai berikut:

Tabel 1 Hipotesis

\begin{tabular}{|l|l|} 
Hipotesis & Keterangan \\
\hline
\end{tabular}




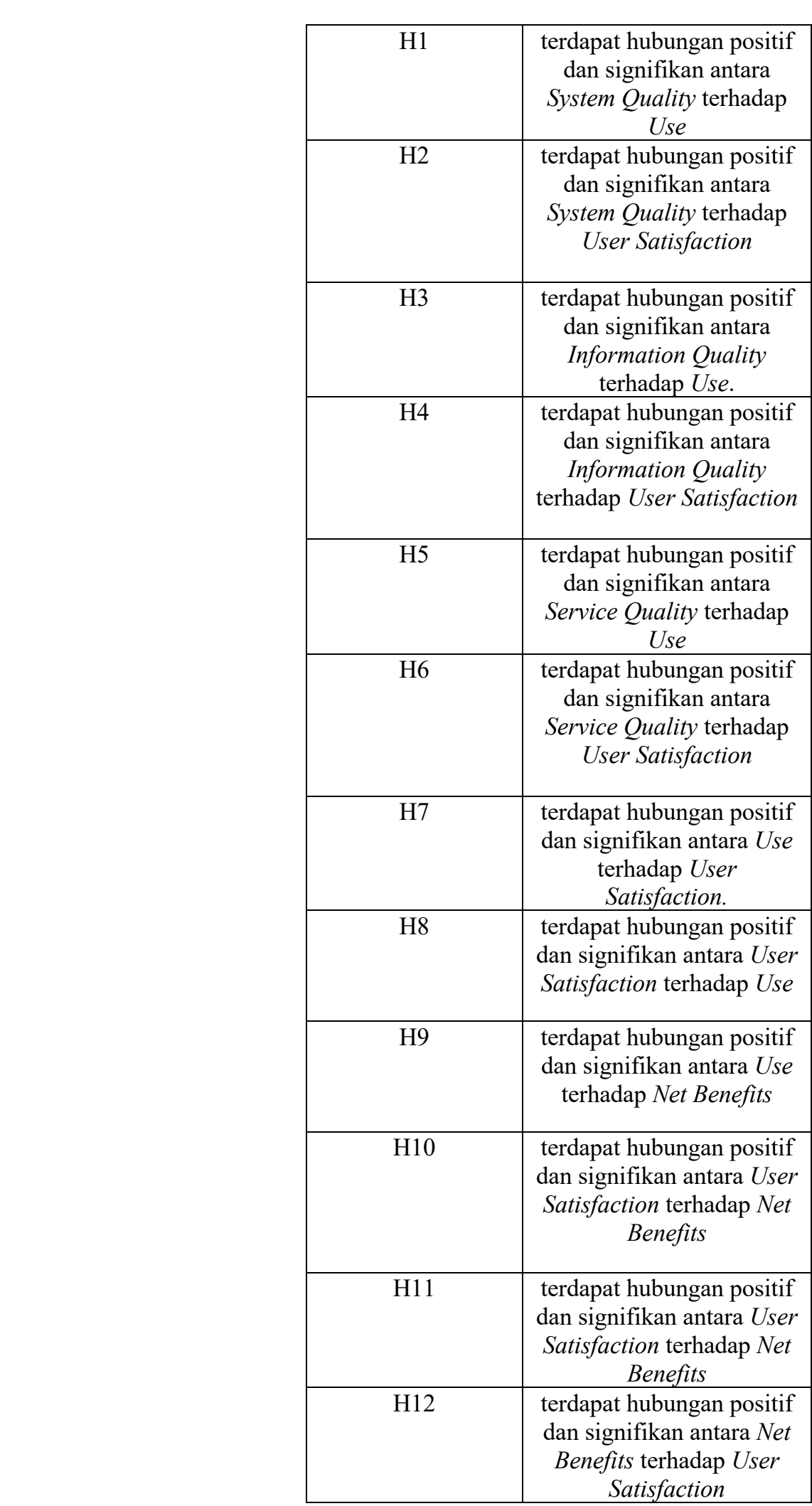

\subsection{Analisis Data}

Analisis data yang digunakan dalam penelitian ini adalah penyebaran kuesioner, analisis statistik, uji regresi, dan uji hipotesis

\section{Hasil dan Pembahasan}

3.1 Uji Hipotesis

Pada tahap ini merupakan tahap pengujian hipotesis berdasarkan hasil nilai path coefficient (koefisien jalur) 
melalui tools GeSCA. Uji hipotesis ini bertujuan untuk membuktikan kebenaran hipotesis yang telah dirumuskan pada tahap perancangan dan perencanaan. Berikut ini merupakan hipotesis yang telah dirumuskan.

Table 2 Perhitungan Uji Hipotesis menggunakan GeSCA

\begin{tabular}{|c|c|c|c|}
\hline \multicolumn{4}{|c|}{ Path Coefficients } \\
\hline & Estimate & SE & CR \\
\hline SQ->U & -0.003 & 0.095 & 0.03 \\
\hline SQ->US & 0.359 & 0.194 & 1.85 \\
\hline IQ->U & 0.175 & 0.106 & 1.65 \\
\hline IQ->US & 0.218 & 0.216 & 1.01 \\
\hline SEQ->U & -0.050 & 0.087 & 0.58 \\
\hline SEQ->US & -0.112 & 0.218 & 0.51 \\
\hline U->US & 0.057 & 0.402 & 0.14 \\
\hline US->U & 0.016 & 0.119 & 0.13 \\
\hline U->NB & 0.864 & 0.050 & $17.41^{*}$ \\
\hline US->NB & 0.005 & 0.080 & 0.07 \\
\hline NB->U & 0.824 & 0.065 & $12.64^{*}$ \\
\hline NB->US & 0.074 & 0.368 & 0.2 \\
\hline
\end{tabular}

Dari tabel path coefficients di atas menunjukkan bahwa hubungan antara variabel laten satu dengan variabel laten yang lainnya berpengaruh positif dan negatif. Variabel laten yang berada di sebelah kiri anak panah mengalami kenaikan sebesar satu satuan maka variabel laten lain yang berada di sebelah kanan anak panah akan naik sebesar nilai estimate.

a) Variabel laten untuk System Quality apabila mengalami kenaikan sebesar satu satuan maka variabel laten Use akan turun sebesar -0.003 dan variabel User Satisfaction akan naik sebesar 0.359.

b) Variabel untuk Information Quality apabila mengalami kenaikan sebesar satu satuan maka variabel laten Use akan naik sebesar 0.175 dan variabel User Satisfaction akan naik sebesar 0.218.

c) Variabel laten untuk Service Quality apabila mengalami kenaikan sebesar satu satuan maka variabel laten Use akan turun sebesar -0.050 dan variabel User Satisfaction akan turun sebesar -0.112.

d) Variabel laten untuk Use apabila mengalami kenaikan sebesar satu satuan maka variabel laten User Satisfaction akan naik sebesar 0.057 dan variabel Net Benefits akan naik sebesar 0.864 .

e) Variabel laten untuk User Satisfaction apabila mengalami kenaikan sebesar satu satuan maka variabel laten Use akan naik sebesar 0.016 dan variabel Net Benefits akan naik sebesar 0.005 .

f) Variabel laten untuk Net Benefits apabila mengalami kenaikan sebesar satu satuan maka variabel laten Use akan naik sebesar 0.824 dan variabel User satisfaction akan naik sebesar 0.074.

Berdasarkan tabel 4.12 diperoleh bahwa nilai estimate path coefficient dan nilai CR. Hal ini kemudian dapat digunakan sebagai acuan untuk menyusun rekapitulasi hasil penerimaan hipotesis penelitian.Hasil dari rekapitulasi penerimaan hipotesis penelitian dapat diliat pada tabel 4.13 berikut :

Table 3 Uji Hipotesis

\begin{tabular}{|c|c|c|}
\hline Hipotesis & Keterangan & Keterangan \\
\hline H1 & terdapat hubungan & Ditolak \\
& positif dan & \\
& signifikan antara & \\
& System Quality & \\
& terhadap Use & \\
\hline H2 & terdapat hubungan & Ditolak \\
& positif dan & \\
& signifikan antara & \\
& System Quality & \\
& terhadap User & \\
& Satisfaction & \\
\end{tabular}




\begin{tabular}{|c|c|c|}
\hline H3 & $\begin{array}{l}\text { terdapat hubungan } \\
\text { positif dan } \\
\text { signifikan antara } \\
\text { Information } \\
\text { Quality terhadap } \\
\text { Use. } \\
\end{array}$ & Ditolak \\
\hline $\mathrm{H} 4$ & $\begin{array}{l}\text { terdapat hubungan } \\
\text { positif dan } \\
\text { signifikan antara } \\
\text { Information } \\
\text { Quality terhadap } \\
\text { User Satisfaction }\end{array}$ & Ditolak \\
\hline H5 & $\begin{array}{l}\text { terdapat hubungan } \\
\text { positif dan } \\
\text { signifikan antara } \\
\text { Service Quality } \\
\text { terhadap Use }\end{array}$ & Ditolak \\
\hline H6 & $\begin{array}{l}\text { terdapat hubungan } \\
\text { positif dan } \\
\text { signifikan antara } \\
\text { Service Quality } \\
\text { terhadap User } \\
\text { Satisfaction }\end{array}$ & Ditolak \\
\hline $\mathrm{H7}$ & $\begin{array}{l}\text { terdapat hubungan } \\
\text { positif dan } \\
\text { signifikan antara } \\
\text { Use terhadap User } \\
\text { Satisfaction. } \\
\end{array}$ & Ditolak \\
\hline $\mathrm{H} 8$ & $\begin{array}{l}\text { terdapat hubungan } \\
\text { positif dan } \\
\text { signifikan antara } \\
\text { User Satisfaction } \\
\text { terhadap Use } \\
\end{array}$ & Ditolak \\
\hline H9 & $\begin{array}{l}\text { terdapat hubungan } \\
\text { positif dan } \\
\text { signifikan antara } \\
\text { Use terhadap Net } \\
\text { Benefits }\end{array}$ & Diterima \\
\hline H10 & $\begin{array}{l}\text { terdapat hubungan } \\
\text { positif dan } \\
\text { signifikan antara } \\
\text { User Satisfaction } \\
\text { terhadap Net } \\
\text { Benefits }\end{array}$ & Ditolak \\
\hline H11 & $\begin{array}{l}\text { terdapat hubungan } \\
\text { positif dan } \\
\text { signifikan antara } \\
\text { User Satisfaction } \\
\text { terhadap Net } \\
\text { Benefits }\end{array}$ & Diterima \\
\hline H12 & $\begin{array}{l}\text { terdapat hubungan } \\
\text { positif dan } \\
\text { signifikan antara } \\
\text { Net Benefits } \\
\text { terhadap User } \\
\text { Satisfaction }\end{array}$ & Ditolak \\
\hline
\end{tabular}

\section{Pembahasan}

Kesuksesan suatu sistem dipengaruhi oleh nilai dari net benefit. Nilai Net Benefit yang akan digunakan 
untuk mengetahui kesuksesan dari Web Desa. Dilihat dari hasil kuesioner responden, nilai mean pada setiap variabel menunjukkan bahwa berada pada tingkat Setuju, hal tersebut dapat diartikan bahwa Web Desa memiliki tingkat kesuksesan yang tinggi atau bisa diartikan berhasil yaitu dengan nilai rata - rata mean diatas 3.

Selanjutnya dilanjutkan dengan mengetahui faktor - faktor apasaja yang dapat mempengaruhi kesuksesan aplikasi tersebut berdasarkan dengan metode ISSM Delone \& Mclean. Dari hasil perhitungan yang sesuai dengan metode Delon \& Mclean dapat di jelaskan dengan nilai dari Net Benefit dipengaruhi oleh Use dan User Satisfaction. Namun. hasil dari pengujian hipotesis menunjukkan nilai Use paling mempengaruhi kesuksesan Net Benefit (Hipotesis 10). Dan Use dipengaruhi oleh Net Benefits (hipotesis 12).

Pada variabel System Quality memiliki nilai Critical Ratio yang sangat rendah sehingga pada variabel System Quality tidak signifikan terhadap Use dan User Statisfaction. Hasil tersebut menunjukkan bahwa dalam mempengaruhi kepuasan pelanggan terdapat aspek kualitas sistem, kualitas sistem dan kualitas layanan yang harus diperhatikan dengan baik oleh pihak atau pengelola Web Desa. Oleh karena itu pihak PPID diharapkan lebih meningkatkan System Quality agar dapat meningkatkan User Satisfaction dan Use lebih tinggi dan memberikan manfaat kepada pengguna Web Desa. Untuk kondisi System Quality yang terletak pada Web Desa saat ini dilihat paling banyak terdapat keluhan seperti pada pertanyaan kuisioner nomer 3 "Koneksi jaringan pada saat mengakses Web Desa tidak pernah terputus" yang memiliki nilai rata - rata paling rendah yaitu 2,77 Sehingga perlu dilakukan peningkatan pada perihal tersebut. Berdasarkan hasil deskriptif yang telah dilakukan. Web Desa memerlukan beberapa perbaikan yang dapat dipertimbangkan pihak PPID untuk Web Desa:

Table 4 Analisis Deskriptif

\begin{tabular}{|l|l|l|l|}
\hline No. & Indikator & Rekomendasi & Deskriptif Statistik \\
\hline 1. & Accessibili- & $\begin{array}{l}\text { Web Desa sebaiknya } \\
\text { diperbaiki agar }\end{array}$ & $\begin{array}{l}\text { Berdasarkan nilai } \\
\text { mean dari hasil } \\
\text { kuesioner diketahui: } \\
\text { koneksi jaringanya } \\
\text { bisa lebih baik lagi }\end{array}$ \\
& s) & $\begin{array}{l}\text { Responden kurang } \\
\text { setuju bila Koneksi } \\
\text { jaringan pada saat } \\
\text { mengakses Web Desa } \\
\text { tidak pernah terputus, } \\
\end{array}$ & $\begin{array}{l}\text { yaitu dengan nilai } \\
\text { mean 2,77 }\end{array}$ \\
\hline
\end{tabular}

\section{Kesimpulan}

Berdasarkan hasil penelitian dan pembahasan yang telah dilakukan. dan rumusan masalah yang dicari maka kesimpulan dari Tugas Akhir ini adalah sebagai berikut:

1. Menurut faktor - faktor yang ada di Information System Success Model (ISSM) yaitu Information Quality. System Quality. Service Quality. Use. User Satisfaction. dan Net Benefits. Dan berdasarkan 12 hipotesis penelitian. diketahui ada 2 hipotesis yang mempengaruhi kesuksesan yaitu:

a) Penggunaan (Use) memberikan hasil positif dan signifikan terhadap Net Benefits. Dengan kata lain jika variabel Use meningkat maka terjadi peningkatan pula terhadap kesuksesan Net Benefits. Hal ini dilihat melalui nilai estimate variabel U terhadap NB pada tabel Path Coefficients yang menunjukkan 0.864 dan memiliki Critical Ratio sebesar 17,41* yang menunjukkan nilai tersebut signifikan.

b) Net Benefits memberikan hasil positif dan signifikan terhadap Penggunaan (Use). Dengan kata lain jika variabel Net Benefits meningkat maka terjadi peningkatan pula terhadap kesuksesan Use. Hal ini dilihat melalui nilai estimate variabel NB terhadap U pada tabel Path Coefficients yang menunjukkan 0.824 dan memiliki Critical Ratio sebesar 12,64* yang menunjukkan nilai tersebut signifikan.

2. Rekomendasi terhadap Web Desa

Berdasarkan hasil dan pembahasan. Web Desa membutuhkan perbaikan pada variabel System Quality pada indikator Accesibility. Beberapa tindakan yang dapat meningkatkan Information Quality diantaranya:

a) Perbaikan koneksi jaringan agar tidak gampang terputus koneksinya saat mengakses web desa

b) Pelayanan dalam flexisibitas respon terhadap perubahan lingkungan yang berlangsung dan sistem memiliki respon yang cepat dengan melakukan update dan upgrade agar web desa memiliki informasi yang dibutuhkan web desa

Beberapa tindakan terhadap Web Desa tersebut dapat meningkatkan kepuasan pengguna secara efektif dan juga efisien. sehingga pengguna Web Desa dapat menerima dampak yang baik dan juga merasa puas atas layanan yang ada. 


\section{Saran}

Dari pelaksanaan penelitian ini dapat diberikan saran untuk penelitian selanjutnya antara lain yaitu penelitian dengan topik yang sama yaitu tentang faktor yang berpengaruh terhadap kesuksesan implementasi layanan Web Desa perlu dilakukan, namun dengan menggunakan metode yang berbeda sehingga dapat menjadi bahan pembanding serta memperkaya hasil penelitian dengan topik yang sama. Juga diharapkan menggunakan tahap pengambilan sampel yang berbeda dan diharapkan lebih meluas sehingga dapat mengetahui pendapat dari pengguna Web Desa.

\section{Daftar Pustaka}

[1] Babbie, E. R. (2016). The Practice of Social Research. Boston: Cengage Learning.

[2] DeLone W \& McLean E.R. (1992). Information System Succes : The Quest for The Dependent Variabel. Information System Research.

[3] DeLone W \& McLean E.R. (2003). The DeLone and McLean Model of Information System Success: A Ten Year Update. Journal of MIS.

[4] Elfada, V. (2018). Evaluasi Kesuksesan "Web Desa pada Kecamatan Maesan" Menggunakan Information System Succes Model (ISSM) (Studi kasus: Petugas Pengelola Informasi Desa (PPID) di Kecamatan Maesan). all.

[5] Fathoni, M. A., Indah, G., \& Suharso, W. (2017). Analisis Pengaruh System Quality, Information Quality, Service Quality Terhadap Net Benefit Pada KRS Online Universitas Muhammadiyah Malang.

[6] Ghozali, K. A. (2013). Generalized Structured Component Analysis (GeSCA) Model Persamaan Berbasis Komponen. Generalized Structured Component Analysis (GeSCA) Model Persamaan Berbasis Komponen.

[7] Hermanto Rohman, M. M. (2016). Membangun Kelembagaan Pusat Pelayanan Informasi Desa.

[8] Jogiyanto. (2007). Model Kesuksesan Sistem Teknologi Informasi.

[9] Leal, R. (2003). Penerapan Model DeLone dan McLean pada Executive Information System (EIS) di Spanyol. all.

[10] Livari. (2005). Penerapan Model DeLone dan McLean pada Sistem Informasi Akuntansi di Universitas Oulo. all.

[11] Makmur, H. R. (2016). Membangun Kelembagaan Pusat Pelayanan Informasi Desa. Surabaya: Pena Salsabila.

[12] Pamungkas, C. A. (2017). Analisis Kesuksesan Sistem Informasi Be-Smart Berdasarkan Metode DeLone dan McLean di Jurusan Pendidikan Teknik Elektronika Universitas Negeri Yogyakarta.

[13] Radityo, Z. (2007). Evaluasi Kesuksesan Aplikasi Sistem Informasi Akademik Berbasis Website (SIMAWEB) di Fakultas Ekonomi Universitas Diponegoro. all.

[14] Rai. (2002). Penerapan Model DeLone dan McLean dalam Sistem Informasi Sukarela di Universitas Midwestern. all.

[15] Redaksi. (2018). Website Desa

[16] Salim, M. I. (2014). Analisis Kesuksesan Sistem Informasi Perpustakaan Dengan Pendekeatan Model DeLone dan McLean di SMK Muhammadiyah 3 Yogyakarta.

[17] Wijayanto, H. (2013). Pengaruh Budaya Organisasi terhadap Kesuksesan Implementasi Enterprise Resources Planning dengan pendekatan Updated DeLone and McLean Information System Success Model. 